\title{
VIABILIDADE ECONÔMICA DO CULTIVO DA ALFACE CRESPA EM MONOCULTURA E EM CONSÓRCIO COM PEPINO
}

\author{
Economic viability of the crisphead lettuce culture in \\ monoculture and intercropping with cucumber
}

\author{
Gilson Silverio da Silva' ${ }^{1}$ Bráulio Luciano Alves Rezende ${ }^{2}$, Arthur Bernardes Cecílio Filho ${ }^{3}$, \\ Aurélio Paes Barros Júnior', Maria Inez Espagnoli Geraldo Martins ${ }^{5}$, Diego Resende de Queirós Porto ${ }^{6}$
}

\begin{abstract}
RESUMO
O cultivo protegido, entre outras vantagens, possibilita diminuir a sazonalidade na oferta e melhorar a qualidade das hortaliças. No entanto, constitui-se em tecnologia de elevado custo, que pode ser atenuado com o aumento na eficiência do uso da área protegida, proporcionado pelo cultivo consorciado. O trabalho foi realizado em casa de vegetação, na Unesp, Jaboticabal, SP, no período de agosto e novembro de 2005, e objetivou-se verificar o custo operacional total (COT) e a rentabilidade líquida da alface crespa 'Verônica' (Lactuca sativa L.) em monocultura e consorciada com pepino japonês 'Hokushin' (Cucumis sativus L.), em ambiente protegido. Os principais itens de custos estimados foram os referentes à operações, insumos e materiais. Para a alface crespa em monocultura e em consórcio, o COT foi de $\mathrm{R} \$ 696,37$ e $\mathrm{R} \$ 295,06 / 614,4 \mathrm{~m}^{2}$, e as produtividades de 890,78 e $822,53 \mathrm{~kg} / 614,4 \mathrm{~m}{ }^{2}$, respectivamente em monocultura e em consórcio e as receitas brutas obtidas foram de $\mathrm{R} \$ 489,93$ e $\mathrm{R} \$ 452,39 / 614,4 \mathrm{~m}^{2}$. Em cultivo protegido, a monocultura de alface teve prejuízo de $\mathrm{R} \$ 206,44 / 614,4 \mathrm{~m}^{2}$, enquanto, em consórcio com pepino, a cultura da alface crespa 'Verônica' teve lucro operacional de $\mathrm{R} \$ 157,33 / 614,4 \mathrm{~m}^{2}$.
\end{abstract}

Termos para indexação: Lactuca sativa, Cucumis sativus, mão-de-obra, casa de vegetação, custo de produção.

\begin{abstract}
The protected culture, among other advantages, made possible to diminish the seasoning in offers and to improve the quality of vegetables. However, one consists in technology of high cost, that it may be attenuated with the increase in the efficiency of the use of the protected area, proportionated for the intercropping. The experiment was carried out at greenhouse at UNESP, JaboticabalSP, in the period of August and November of 2005, with the aim of evaluating the operational cost (COT) and the profitability of the crisphead lettuce "Verônica" (Lactuca sativa L.) in monoculture and in intercropping with the Japanese cucumber "Hokushin" (Cucumis sativus L.), in protected environment. The main cost items analyzed were the operational cost, the agricultural amendments and the materials cost. For the crisphead lettuce in monoculture and in intercropping, the COT was $\mathrm{R} \$ 696,37$ and $\mathrm{R} \$ 295,06 / 614,4$ $\mathrm{m}^{2}$ respectively and the productivity was 822.53 and $890.78 \mathrm{~kg} / 614,4 \mathrm{~m}^{2}$. In monoculture and in intercropping the gross incomes were $R \$ 489,93$ and $R \$ 452,39 / 614,4 \mathrm{~m}^{2}$ respectively. It was verified a loss of $R \$ 206,44 / 614,4 \mathrm{~m}^{2}$ in the crisphead lettuce monoculture and an operational profit of $\mathrm{R} \$ 157,33 / 614,4 \mathrm{~m}^{2}$ in protected environment when in intercropping with cucumber.
\end{abstract}

Index terms: Lactuca sativa, Cucumis sativus, hand labor, greenhouse, production cost.

(Recebido em 5 de novembro de 2007 e aprovado em 4 de abril de 2008)

\section{INTRODUÇÃO}

Pertencente à família Asteraceae (Compositae), a alface é considerada, por Costa \& Sala (2005), a hortaliça folhosa de maior importância no Brasil, com 35.000 ha plantados. Seu cultivo é de maneira intensiva e, geralmente, praticado como agricultura familiar, que é responsável pela geração de cinco empregos diretos por hectare.

No Brasil, o consumo de alface encontra-se em sexto lugar em relação às demais hortaliças (GOTO, 1998). Segundo dados do Agrianual (2007), o volume de alface comercializada no ano de 2005, na Companhia de Entrepostos e Armazéns Gerais de São Paulo (CEAGESP),

\footnotetext{
Engenheiro Agrônomo - Departamento de Produção Vegetal/PV - Universidade Estadual Paulista/UNESP - Via de Acesso Paulo Donato Castellane, $\mathrm{s} / \mathrm{n}$ - 14884-900 - Jaboticabal, SP - silverios@hotmail.com

Engenheiro Agrônomo, Doutor, Professor - Departamento de Fitotecnia e Fitossanidade/DEFITO - Universidade Estadual de Ponta Grossa/UEPG Avenida Carlos Cavalcanti, 4748 - Uvaranas - 84030-900 - Ponta Grossa, PR - blrezende@ig.com.br

${ }^{3}$ Engenheiro Agrônomo, Doutor, Professor - Departamento de Produção Vegetal/PV - Universidade Estadual Paulista/UNESP - Via de Acesso Paulo Donato Castellane, s/n - 14884-900 - Jaboticabal, SP - rutra@fcav.unesp.br

${ }^{4}$ Engenheiro Agrônomo, Pós-Doutorando em Fitotecnia - Departamento de Ciências Vegetais/CV - Universidade Federal do Semi-Árido/UFERSA Br110, Km 47 - Presidente Costa e Silva - 59625-900 - Mossoró, RN - aureliojr02@yahoo.com.br

${ }_{5}^{5}$ Médica Veterinária, Doutora, Professora - Departamento de Economia Rural/ER - Universidade Estadual Paulista/UNESP - Via de Acesso Paulo Donato Castellane, s/n - 14884-900 - Jaboticabal, SP - minezesp@fcav.unesp.br

${ }^{6}$ Engenheiro Agrônomo, Mestre - Departamento de Produção Vegetal/PV - Universidade Estadual Paulista/UNESP - Via de Acesso Paulo Donato Castellane, s/n - 14884-900 - Jaboticabal, SP - portodrq@hotmail.com
} 
foi de 26.767 toneladas, sendo que 48,68\% desse volume comercializado foi do grupo crespa.

Nos últimos anos, pesquisadores têm estudado um sistema de cultivo com potencial de adoção na produção de hortaliças, o cultivo consorciado, que tem se mostrado promissor para alface em associação com outras hortaliças, tais como Cecílio Filho (2005) que consorciou tomate e alface; Rezende et al. (2005b), com pimentão, repolho, rúcula, alface e rabanete; Costa (2006), alface e rúcula; Oliveira et al. (2005), cenoura com rúcula e alface, sendo que todos esses autores verificaram a viabilidade agronômica do cultivo consorciado.

O cultivo consorciado é definido como duas ou mais culturas, com diferentes ciclos e arquiteturas vegetativas, exploradas, concomitantemente, na mesma área. Ressalte-se que as culturas não são necessariamente semeadas ou plantadas ao mesmo tempo, mas, durante apreciável parte de seus períodos vegetativos, há uma simultaneidade, forçando uma interação entre elas nos sistemas de consórcio (VIEIRA, 1998).

À tecnologia do cultivo protegido aliado ao cultivo consorciado vem se somar às novas tecnologias empregadas na agricultura, com a finalidade de buscar respostas ao desafio de produzir alimentos de maneira competitiva e sustentável, com maior produtividade, qualidade e lucratividade e com um mínimo de impacto ao meio ambiente, assim, diminuindo os riscos e as incertezas do setor agrícola (DAREZZO et al., 2004).

Alguns autores relataram a redução do custo de vários itens relacionados à produção de hortaliças como insumos e operações para a cultura consorciada quando comparada com sua monocultura. Rezende et al. (2005a,b) verificaram, pela análise econômica, que as culturas consorciadas tiveram seus custos de produção reduzidos, quando comparados às suas monoculturas. Outros autores como Barros Júnior et al. (2005) e Cecílio Filho \& May (2002) também encontraram aumento na receita líquida nos cultivos consorciados.

A produção de hortaliças é caracterizada pelo alto investimento por hectare explorado, são espécies de ciclo curto, com uso intensivo do solo, exigem tratos culturais bem particulares, alocam excessiva mão-de-obra, apresenta alto risco; enfim, é uma atividade que requer grande capacidade técnica e administrativa do produtor. Diante de tantas exigências, é importante para o produtor conhecer o custo de produção dessa cultura para orientar as futuras ações do olericultor empresário (FILGUEIRA, 2003).

Por meio deste estudo, objetivou-se determinar os custos de operacionais totais das culturas de alface (Lactuca sativa L.) em monocultura e em consórcio com pepino (Cucumis sativus L.) e verificar a viabilidade econômica dos dois sistemas de cultivo, em ambiente protegido.

\section{MATERIAL E MÉTODOS}

Neste estudo, a produtividade e os coeficientes técnicos da cultura da alface, em monocultura e consórcio, foram obtidos em experimento conduzido no período de 27 de agosto a 19 de novembro de 2005 . O experimento foi realizado em casa de vegetação de $48 \mathrm{~m}$ de comprimento e $12,8 \mathrm{~m}$ de largura $\left(614,4 \mathrm{~m}^{2}\right)$, modelo teto em arco, com pédireito de $3 \mathrm{~m}$, coberta com filme de polietileno de baixa densidade, transparente, de 150 micrômetros de espessura, aditivado contra raios ultravioleta, localizada na Universidade Estadual Paulista (UNESP), Faculdade de Ciências Agrárias e Veterinárias, no Setor de Olericultura e Plantas Aromático-Medicinais, em Jaboticabal, SP.

O clima de Jaboticabal é classificado como subtropical com chuvas de verão, e inverno relativamente seco. Apresenta médias anuais de $1.424,6 \mathrm{~mm}, 22,2^{\circ} \mathrm{C}, 28,9^{\circ} \mathrm{C}$ e $16,8^{\circ} \mathrm{C}$, respectivamente, para precipitação pluvial e temperaturas média, máxima e mínima (RESENHA..., 2007).

O solo da área, segundo classificação da Embrapa (1999), corresponde ao Latossolo Vermelho Eutroférrico típico de textura muito argilosa, a moderado cauliníticooxídico, relevo suave ondulado a ondulado.

$\mathrm{O}$ pepineiro foi cultivado em fileira dupla com espaçamento de $1,20 \times 0,60 \times 0,50 \mathrm{~m}$ e alface crespa no espaçamento de $0,25 \times 0,25 \mathrm{~m}$ (Figura 1). O híbrido de pepino japonês utilizado foi o 'Hokushin', enquanto a cultivar de alface crespa foi a 'Verônica'.

O preparo do solo, para todos os sistemas de cultivo, constou da limpeza do terreno com aplicação de herbicida (pulverizador costal de 20 litros) para a eliminação de plantas daninhas e uma aração, utilizando-se um arado de três discos de 26".

De acordo com a análise química do solo, não foi realizada a calagem, uma vez que a saturação por bases do solo encontrava-se acima da recomendada (80\%).

A adubação orgânica de plantio demandou a distribuição manual de 1,3 tonelada de esterco bovino e rotoencanteirador na incorporação.

As mudas de alface crespa 'Verônica', produzidas em bandejas de 288 células, foram transplantadas no mesmo dia do transplante do pepino, com quatro folhas definitivas. A colheita da alface foi realizada 39 dias após o transplante (DAT)

$\mathrm{Na}$ atividade adubação química de plantio e cobertura, considerou-se a necessidade de mão-de-obra para a distribuição dos fertilizantes químicos, 


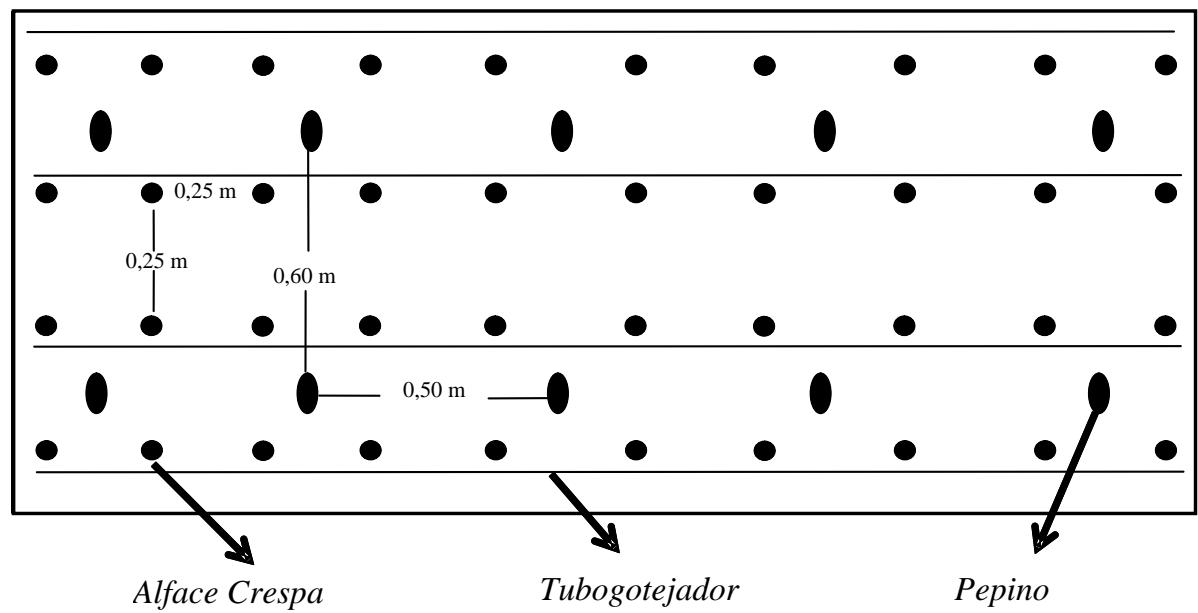

Figura 1 - Representação gráfica de uma unidade experimental e disposição das culturas em consórcio, pepino (fileira dupla - 1,20 x 0,60 x 0,50 m) e alface crespa $(0,25 \times 0,25 \mathrm{~m})$, Jaboticabal-SP, 2005.

separadamente para cada cultura, de acordo com as recomendações de Trani et al. (1997a,b). No cultivo consorciado, a adubação de plantio foi realizada com base na cultura mais exigente (pepino), aplicando $35 \mathrm{~g} / \mathrm{m}^{2}$ da fórmula 12-6-12. Para a alface crespa 'Verônica' foram realizadas, respectivamente, duas adubações de cobertura em todos os sistemas de cultivo (consórcio e monocultura), com a aplicação de 2,0 g/planta de nitrato de amônio, respectivamente aos 15 e 30 DAT.

O encanteiramento correspondeu ao levantamento de seis canteiros de $48 \mathrm{~m}$ de comprimento, com rotoencanteirador de $1,20 \mathrm{~m}$, com seis enxadas, onde foram transplantadas as mudas de alface.

A marcação do local de plantio foi realizada manualmente para o transplante das mudas de alface e de pepino, nos espaçamentos citados.

Foram realizadas capinas manuais dentro e entre canteiros. Para a cultura da alface crespa foram realizadas três capinas em monocultura, enquanto em consórcio foram realizadas duas capinas, tendo seu custo computado na cultura principal.

Os fungicidas e inseticidas foram aplicados com pulverizador costal $(20 \mathrm{~L})$, de acordo com a necessidade da cultura. Foram realizadas três aplicações de defensivos para alface crespa em monocultura bem como no cultivo consorciado.

O sistema de irrigação constituiu-se da linha principal, linhas secundárias de tubogotejadores e por moto-bomba de $1 \mathrm{cv}$ de potência. Para a alface crespa foram utilizadas quatro fitas, ou seja, uma por linha de plantio. No cultivo consorciado, não houve diferença quanto ao número de fitas de tubogotejador em relação à monocultura. Esse sistema de irrigação utilizado não depende da mudança dos tubogotejadores na casa de vegetação e, portanto, na estimativa de mão-de-obra comum foi considerado somente o tempo requerido para ligar e desligar o sistema, além de alguns reparos. Considerou-se um tempo médio de irrigação de 30 minutos por dia, durante todo o período de crescimento das culturas, tanto em monocultura quanto em consórcio.

$\mathrm{Na}$ atividade de pós-colheita foram considerados a lavagem, a classificação e o acondicionamento da alface para a comercialização.

Em virtude da cultura do pepino ser considerada como a cultura principal, no sistema consorciado os custos relativos à mão-de-obra, máquinas, implementos e insumos comuns às duas culturas como: limpeza do terreno, aração, levantamento dos canteiros, capinas, adubação de plantio, irrigação e aplicação de defensivos foram computados a essa cultura, pois seriam atividades naturalmente desenvolvidas.

$\mathrm{Na}$ determinação do custo operacional total (COT), utilizou-se a estrutura do custo operacional de produção proposta por Matsunaga (1976).

Os preços nominais de todos os itens de produção foram cotados para o mês de agosto de 2006 e corrigidos pelo Indice Geral de Preços - Disponibilidade Interna (IGPDI), para valores (R\$) de fevereiro de 2007.

Para a análise do custo de produção das culturas, todos os coeficientes técnicos referentes à implantação e condução das culturas foram obtidos durante a realização do experimento. 
Os valores unitários de cada item, referentes a fevereiro de 2007, foram calculados da seguinte forma:

a) custo de mão-de-obra: o salário da mão-de-obra foi obtido junto ao Sindicato dos Trabalhadores Rurais de Jaboticabal-SP, de R \$394,87 para mão-de-obra comum e de $\mathrm{R} \$ 434,36$ para tratorista, para 200 horas trabalhadas no mês, mais encargos sociais assumidos pelo empregador, que equivalem a $43 \%$ do valor do salário. Dessa forma, os custos-hora determinados foram, respectivamente, de R \$ 2,82 e R \$ 3,11 para mão-de-obra comum e para tratorista;

b) preços de insumos: os preços nominais dos insumos foram obtidos na região de Jaboticabal-SP, enquanto os preços de alguns equipamentos (trator MF$27575 \mathrm{cv}$ e arado) foram obtidos no banco de dados do Instituto de Economia Agrícola - IEA (IEA, 2006).

c) custo e depreciação hora da máquina, implementos e custos das operações: no custo-hora de máquinas (CHM), trator MF 275 (72 cv), foram considerados os gastos efetuados com combustível (c), mais um valor estimado para reparos (r), manutenção $(\mathrm{m})$, garagem $(\mathrm{g})$ e uma taxa de seguro (s), da seguinte forma: $\mathrm{CHM}=\mathrm{s}+\mathrm{g}+$ $\mathrm{r}+\mathrm{m}+\mathrm{c}$, sendo que o seguro, garagem e os reparos, foram respectivamente, de $0,75 \%, 1 \%$ e $10 \%$, ao ano, do valor da máquina, considerando 1.000 horas de uso da máquina, além dos gastos de manutenção $(\mathrm{m})$. No cálculo da manutenção do trator 275 (72 cv), considerou-se o custo relativo aos lubrificantes (óleos e graxas) e itens de manutenção da máquina (filtros), considerando-se o período de troca sugerido pelo fabricante. Dessa forma, o custo-hora de um trator MF-275 de $72 \mathrm{cv}$, sem depreciação e consumo de combustível, foi de $\mathrm{R} \$ 12,07$.

Para o custo-hora de implementos (CHI), consideraram-se o consumo de graxa e reparos representados da seguinte forma: $\mathrm{CHI}=\mathrm{r}+\mathrm{gr}$; onde $\mathrm{r}=$ reparos, correspondente a $10 \%$ ao ano do valor do implemento, e gr indica custo da graxa ( Tabela 1).

A depreciação foi calculada com base no método linear, onde o bem é desvalorizado durante sua vida útil a uma cota constante, conforme a seguinte fórmula: $\mathrm{D}=$ $(\mathrm{Vi}-\mathrm{Vf}) / \mathrm{N} . \mathrm{H}$, sendo D a depreciação em R $\$$ /hora ou dia; Vi o valor inicial (novo); $\mathrm{Vf}$ o valor final; $\mathrm{N}$ a vida útil (anos) e $\mathrm{H}$ as horas de uso no ano. Considerou-se um valor final para o trator igual a $20 \%$ do valor novo, enquanto para os implementos foi considerado igual a zero (Tabela 1).

No custo-hora das operações, utilizou-se o somatório dos custos-hora com trator, implementos e combustível gastos em cada operação (Tabela 1).

Tabela 1 - Valores unitários dos itens utilizados na determinação do custo operacional de produção das culturas estudadas no experimento, Jaboticabal-SP, 2005.

\begin{tabular}{|c|c|c|c|c|c|}
\hline Itens & $\begin{array}{l}\text { Valor novo } \\
(\mathrm{R} \$)^{1}\end{array}$ & $\begin{array}{l}\text { Vida útil } \\
\text { (ano) }\end{array}$ & Uso no ano & $\mathrm{CH}(\mathrm{R} \$)$ & $\begin{array}{c}\text { Depreciação } \\
\text { (R\$/h ou dia) }\end{array}$ \\
\hline Trator $275(72 \mathrm{cv})$ & $90.691,97$ & 10 & $1.000 \mathrm{~h}^{2}$ & 12,07 & 7,26 \\
\hline Rotoencanteirador & $7.076,92$ & 8 & $480 \mathrm{~h}$ & 2,01 & 1,84 \\
\hline Pulverizador Costal (20 1) & 153,85 & 5 & $120 \mathrm{~h}$ & 0,13 & 0,26 \\
\hline Motobomba - 1cv & 441,03 & 10 & $300 \mathrm{~h}$ & 0,15 & 0,15 \\
\hline Arado 3 disco de 26" & $4.403,90$ & 7 & $480 \mathrm{~h}$ & 1,25 & 1,31 \\
\hline Carrinho de mão & 123,08 & 4 & $270 \mathrm{~h}$ & 0,84 & 0,11 \\
\hline Casa de vegetação $\left(614,4 \mathrm{~m}^{2}\right)$ & $10.285,07$ & 10 & 365 dias & - & 2,82 \\
\hline Tubogotejador - pepino 2 linhas (588 m) & 423,36 & 2 & 304 dias & - & 0,70 \\
\hline Tubogotejador - pepino 1 linha (294 m) & 211,68 & 2 & 304 dias & - & 0,35 \\
\hline Tubogotejador - alface (1176 m) & 846,72 & 2 & 304 dias & - & 1,39 \\
\hline Moirões - pepino 1 linha (24 u.) & 492,24 & 15 & 330 dias & - & 0,10 \\
\hline Moirões - pepino 2 linhas (48 u.) & 984,48 & 15 & 330 dias & - & 0,20 \\
\hline Catracas - pepino 2 linhas (144 u.) & 318,24 & 8 & 330 dias & - & 0,12 \\
\hline Catracas - pepino 1 linha (72 u.) & 159,12 & 8 & 330 dias & - & 0,06 \\
\hline \multicolumn{6}{|c|}{ Operações } \\
\hline $\mathrm{M}+\mathrm{I}^{3}$ & \multicolumn{2}{|c|}{ Consumo combustível (1/h) } & \multicolumn{2}{|c|}{ Preço combustível (R $\$ / 1)$} & $\begin{array}{c}\mathrm{CH}^{4} \\
\mathrm{M}+\mathrm{I}(\mathrm{R} \$)\end{array}$ \\
\hline Trator + Arado & \multicolumn{2}{|c|}{8} & \multicolumn{2}{|c|}{1,98} & 29,91 \\
\hline Encanteiramento Trator + Rotoencanteirador & \multicolumn{2}{|c|}{9} & \multicolumn{2}{|c|}{1,98} & 31,14 \\
\hline
\end{tabular}

${ }^{1}$ Preço corrigido pelo IGP-DI, base: fevereiro $/ 2007=100 ;{ }^{2} \mathrm{~h}=$ hora; ${ }^{3} \mathrm{M}+\mathrm{I}=$ máquina e implemento; ${ }^{4} \mathrm{CH}=$ custo hora sem depreciação. 
Para o cálculo da receita considerou-se a produção obtida nos dois sistemas e o preço médio da alface crespa $(\mathrm{R} \$ 0,55 / \mathrm{kg})$, correspondente à classificação Especial, cotado no setor atacadista Companhia de Entrepostos e Armazéns Gerais de São Paulo (CEAGESP), no mês da colheita (CEAGESP, 2007). Desse preço foi deduzido 30\%, valor estimado das despesas com embalagem, frete, carga e descarga, contribuição especial da seguridade social rural (CESSR) e comissões. O lucro operacional (LO) foi obtido pela diferença entre a receita bruta $(\mathrm{RB})$ e o custo operacional total (COT). O lucro operacional indica o valor disponível para remunerar capital, empresário e o risco.

\section{RESULTADOS E DISCUSSÃO}

Os custos operacionais totais (COT) da alface crespa em monocultura e consorciada com pepino japonês foram estimados em $\mathrm{R} \$ 696,37 / 614,4 \mathrm{~m}^{2}$ e $\mathrm{R} \$ 295,06 / 614,4$ $\mathrm{m}^{2}$, respectivamente (Tabela 2). O COT apresentou redução de $57,62 \%$ no cultivo consorciado e está em acordo com Cecílio Filho (2005) e Rezende et al. (2005c), que também observaram redução no COT de alface crespa em consórcio com tomate, respectivamente de $39,5 \%$ e $70 \%$ em relação à monocultura.

O custo da alface, quando consorciada com pepino, apresentou redução em todos os itens: operações, insumos, materiais e depreciação. Entre as operações, verifica-se que as relativas ao preparo do solo, adubações de plantio, capinas, aplicação de defensivos e irrigação não têm seus custos atribuídos à alface quando consorciada, por serem atribuídos à cultura principal, no caso o pepino.

Assim, o custo da alface consorciada apresentou redução de 56,06\% nas operações, 36,18\% em insumos e materiais e $84,15 \%$ na depreciação quando comparado com a monocultura.

O item com maior participação no custo da monocultura da alface crespa foi a mão-de-obra, representando $30,54 \%$ do COT, seguida pelas mudas $(17,20 \%)$ e depreciação da casa de vegetação $(16,20 \%)$, e os demais insumos e as depreciações (sistema de irrigação e implementos) participaram com 13,74 e 11,29\%, respectivamente.

O consórcio da alface crespa com pepino demandou 39,06 horas/614,4 m² de mão-de-obra comum, mas não houve gasto com mão-de-obra tratorista, herbicida, defensivos, espalhante adesivo e depreciação da casa de vegetação.

$\mathrm{O}$ item que mais onerou o COT da alface em consórcio foi a aquisição das mudas $(40,60 \%)$, seguida pela mão-de-obra comum, relativa principalmente à colheita e pós-colheita $(37,33 \%)$, depreciações $(10,28 \%)$, fertilizantes $(6,0 \%)$ e gastos com máquinas e implementos $(5,78 \%)$. De acordo com Cecílio Filho (2005), que estudou a viabilidade econômica do consórcio de alface e tomate, o componente que mais onerou o COT foi a mão-de-obra demandada pela cultura da alface, nas operações de colheita e pós-colheita.

A maior necessidade de mão-de-obra para a alface em monocultura e consórcio deu-se nas operações de colheita e pós-colheita (lavagem, classificação e acondicionamento), representando aproximadamente de $30 \%$ e $53,12 \%$, respectivamente, do total de horas utilizadas de mão-de-obra comum. Rezende et al. (2005b), avaliando a viabilidade econômica das culturas de pimentão, repolho, alface, rabanete e rúcula em cultivo consorciado, na primavera-verão, também constataram maior necessidade de mão-de-obra comum nas operações de colheita e pós-colheita. Quando se compara os sistemas de cultivo, o consórcio proporcionou uma redução de $46,76 \%$ no custo de mão-de-obra comum. A redução se deve à algumas operações que foram utilizadas na monocultura (aração, adubação de plantio, aplicação de esterco, capina manual, aplicação de defensivos e irrigação) e que, quando em consórcio, foram atribuídas ao COT da cultura principal.

Barros Júnior et al. (2005), avaliando a rentabilidade das culturas de alface, rabanete, rúcula e repolho em monocultura e consorciada com pimentão, também verificaram considerável economia no custo de produção no cultivo consorciado em relação à monocultura, pois a cultura secundária não demandou gastos com limpeza do terreno, aração, gradagem e encanteiramento, os quais foram realizados para a implantação da cultura principal.

O custo com máquinas e implementos na monocultura foi $77,79 \%$ superior ao do cultivo consorciado, porque as operações de preparo de solo tiveram seus custos atribuídos à cultura principal.

$\mathrm{O}$ item que mais onerou os custos com insumos e materiais, tanto para a monocultura quanto para o consórcio, foi aquisição de mudas, representando 55,61\% e $87,13 \%$, respectivamente. Para alface em monocultura, o custo com esterco de bovino (adubação orgânica) (15,47\%) foi o segundo componente que mais onerou os custos com insumos e materiais, fato que não aconteceu para a alface em consórcio, pois não teve custo com defensivos, uma vez que foi favorecida pelo controle fitossanitário realizado na cultura do pepino, em sua fase inicial após o transplante. A alface consorciada também aproveitou a adubação orgânica e mineral de plantio realizada para a cultura do pepino. Comparando-se a monocultura com o 
Tabela 2 - Coeficientes técnicos e custo operacional total para a produção de alface crespa 'Verônica' em monocultura e consorciada com pepino japonês 'Hokushin', em casa de vegetação de 614,4 m², Jaboticabal-SP, 2005.

\begin{tabular}{|c|c|c|c|c|c|c|}
\hline \multirow{3}{*}{ Itens } & \multicolumn{3}{|c|}{ Monocultura } & \multicolumn{3}{|c|}{ Consórcio } \\
\hline & \multicolumn{6}{|c|}{ 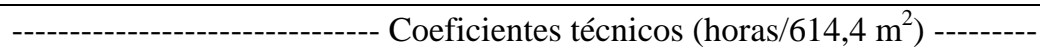 } \\
\hline & $\mathrm{MOC}^{1}$ & $\mathrm{MOTr}^{2}$ & $\mathrm{M}+\mathrm{I}^{3}$ & MOC & MOTr & $\mathrm{M}+\mathrm{I}$ \\
\hline \multicolumn{7}{|l|}{ 1-Operações } \\
\hline Limpeza do terreno & 1,00 & - & 1,00 & 0,00 & - & - \\
\hline Aração & - & 0,70 & 0,70 & 0,00 & - & - \\
\hline Encanteiramento & - & 0,85 & 0,85 & 0,00 & - & - \\
\hline Adubação de plantio & 1,15 & - & & 0,00 & - & - \\
\hline Aplicação de adubo orgânico & 11,00 & 0,30 & - & 0,00 & - & - \\
\hline Montagem do sistema de irrigação & 9,00 & - & - & 4,50 & - & - \\
\hline Marcação do local de transplante & 3,07 & - & - & 3,07 & - & - \\
\hline Transplante & 4,60 & - & - & 4,60 & - & - \\
\hline Capina manual & 7,60 & - & - & 0,00 & - & - \\
\hline Adubação de cobertura & 6,14 & - & - & 6,14 & - & - \\
\hline Aplicação de defensivos & 4,05 & - & 4,05 & 0,00 & - & - \\
\hline Irrigação & 5,00 & - & 20,00 & 0,00 & - & - \\
\hline Colheita e Pós-colheita & 20,75 & - & 20,32 & 20,75 & - & 20,32 \\
\hline Total de Horas & 73,36 & 1,85 & 46,92 & 39,06 & - & 20,32 \\
\hline A - Custo das operações & 206,88 & 5,75 & 76,87 & 110,15 & - & 17,07 \\
\hline 2 - Insumos e materiais & Quant. & \multicolumn{2}{|c|}{ Valor $(\mathrm{R} \$)$} & Quant. & \multicolumn{2}{|c|}{ Valor $(\mathrm{R} \$)$} \\
\hline Formulação 12-06-12 (kg) & 10,00 & \multicolumn{2}{|c|}{8,70} & - & \multicolumn{2}{|c|}{-} \\
\hline Nitrato de Amônio (kg) & 18,43 & \multicolumn{2}{|c|}{17,69} & 18,43 & \multicolumn{2}{|c|}{17,69} \\
\hline Esterco de bovino $(\mathrm{t})$ & 1,30 & \multicolumn{2}{|c|}{33,33} & - & \multicolumn{2}{|c|}{-} \\
\hline Herbicida (1) & 0,50 & \multicolumn{2}{|c|}{9,33} & - & \multicolumn{2}{|c|}{-} \\
\hline Mudas (u.) & 4,608 & \multicolumn{2}{|c|}{119,81} & 4,608 & \multicolumn{2}{|c|}{119,81} \\
\hline Espalhante adesivo (1) & 0,18 & \multicolumn{2}{|c|}{1,11} & - & \multicolumn{2}{|c|}{-} \\
\hline Defensivos & - & \multicolumn{2}{|c|}{25,49} & - & \multicolumn{2}{|c|}{-} \\
\hline $\mathrm{B}$ - Custo dos insumos e materiais & \multicolumn{3}{|c|}{215,46} & \multicolumn{3}{|c|}{137,50} \\
\hline Custo operacional efetivo $(\mathrm{A}+\mathrm{B})$ & \multicolumn{3}{|c|}{504,96} & \multicolumn{3}{|c|}{264,72} \\
\hline Custo da Depreciação (outras) & \multicolumn{3}{|c|}{78,61} & \multicolumn{3}{|c|}{30,34} \\
\hline (Casa de vegetação) & \multicolumn{3}{|c|}{112,80} & \multicolumn{3}{|c|}{-} \\
\hline Custo operacional total $\left(\mathrm{R} \$ / 614,4 \mathrm{~m}^{2}\right)$ & \multicolumn{3}{|c|}{696,37} & & 295,06 & \\
\hline
\end{tabular}

${ }^{1} \mathrm{MOC}$ - mão-de-obra comum; ${ }^{2} \mathrm{MOTr}$ - mão-de-obra tratorista; ${ }^{3} \mathrm{M}+\mathrm{I}$ - gastos com máquinas e/ou implementos; ${ }^{4}$ No custo hora máquinas foram considerados combustível, manutenção, reparos, garagem e seguro.

Fonte: UNESP/FCAV, Jaboticabal-SP, 2005.

consórcio, houve uma redução de $36,18 \%$ no custo com insumos e materiais.

No item depreciação, o valor correspondente à casa de vegetação não foi pequeno, $\mathrm{R} \$ 112,80$ (Tabela 2). Quando em monocultura, a alface tem para si todo o ônus dessa estrutura; contudo, quando em consórcio com o pepino, o custo é atribuído a esse, que é a cultura principal.
No item depreciação, verificou-se redução significativa entre os dois sistemas uma vez que o valor representa a casa de vegetação e foi totalmente atribuída à cultura do pepino.

A produtividade da alface crespa em monocultura foi de $890,78 \mathrm{~kg} / 614,4 \mathrm{~m}^{2}$, enquanto em consórcio foi de $822,53 \mathrm{~kg} / 614,4 \mathrm{~m}^{2}$, o que proporcionaram receitas brutas, respectivamente, de $\mathrm{R} \$ 489,93$ e $\mathrm{R} \$ 452,39 / 614,4 \mathrm{~m}^{2}$. 
Verificou-se que a alface crespa em monocultura teve seu custo operacional total $\left(\mathrm{R} \$ 696,37 / 614,4 \mathrm{~m}^{2}\right)$ superior à receita bruta ocorrendo um prejuízo de $\mathrm{R} \$ 206,44 /$ $614,4 \mathrm{~m}^{2}$. O resultado permite afirmar que a alface crespa em monocultura, sob ambiente protegido durante esse período, não é interessante ao produtor, devido principalmente ao alto custo de manutenção da casa de vegetação e o baixo preço obtido da hortaliça nessa época (R\$ 0,55/kg). Rezende et al. (2005c), durante o período de abril a agosto de 2002, observaram também uma baixa rentabilidade $\left(\mathrm{R} \$ 30,56 / 625 \mathrm{~m}^{2}\right)$ na monocultura de alface crespa em ambiente protegido.

Encontrou-se um lucro operacional de R\$ 157,33/ $614,4 \mathrm{~m}^{2}$ para o consórcio. Rezende et al. (2005c), consorciando tomate com alface, também encontraram um lucro operacional para alface em consórcio de $\mathrm{R} \$$ $293,71 / 614,4 \mathrm{~m}^{2}$.

\section{CONCLUSÕES}

A alface crespa, em cultivo consorciado, tem menor custo operacional total do que em monocultura.

A cultura da alface crespa em consórcio com pepino japonês teve lucro operacional de $\mathrm{R} \$ 157,33 / 614,4 \mathrm{~m}^{2}$, enquanto em monocultura houve prejuízo de $\mathrm{R} \$ 206,44 /$ $614,40 \mathrm{~m}^{2}$.

O consórcio tornou a cultura da alface viável economicamente, no ambiente e época de cultivo avaliados.

\section{AGRADECIMENTOS}

A FAPESP, pela concessão de auxílio à pesquisa, processo 2004/14231-5.

\section{REFERÊNCIAS BIBLIOGRÁFICAS}

AGRIAnUAl. Anuário estatístico da agricultura brasileira. São Paulo: FNP Consultoria \& Comércio, 2007.

BARROS JÚNIOR, A. P.; REZENDE, B. L. A.; CECÍLIO FILHO, A. B.; MARTINS, M. I. E. G.; COSTA, C. C.; FELTRIM, A. L.; SILVA, G. S. Rentabilidade das culturas de alface, rabanete, rúcula e repolho em cultivo solteiro e consorciadas com pimentão.In: CONGRESSO BRASILEIRO DE OLERICULTURA, 45., 2005, Fortaleza, CE. Anais.. Fortaleza, 2005. CD-ROM.

CECÍLIO FILHO, A. B. Cultivo consorciado de hortaliças: desenvolvimento de uma linha de pesquisa. 2005. $135 \mathrm{f}$. Tese (Livre-docência) - Universidade Estadual Paulista, Jaboticabal, 2005.
CECÍLIO FILHO, A. B.; MAY, A. Produtividade das culturas de alface e rabanete em função da época de estabelecimento do consórcio, em relação a seus monocultivos. Horticultura Brasileira, Brasília, v. 20, n. 3, p. 501-504, set. 2002.

COMPANHIA DE ENTREPOSTOS E ARMAZÉNS GERAIS DE SÃO PAULO. Cotações de preços. São Paulo, 2007. Disponível em:' $\langle$ http://Www.ceagesp.com.br Acesso em: 1 fev. 2007.

COSTA, C. C. Consórcio de alface e rúcula: aspectos produtivos e econômicos. 2006. 83 f. Tese (Doutorado em Produção Vegetal) - Universidade Estadual Paulista, Jaboticabal, 2006.

COSTA, C. P.; SALA, F. C. A evolução da alfacicultura brasileira. Horticultura Brasileira, Brasília, v. 23, n. 1, jan./ mar. 2005. Verso da capa.

DAREZZO, R. J.; AGUIAR, R. L.; AGUILERA, G. A. H.; ROZANE, D. E.; SILVA, D. J. H. Cultivo em ambiente protegido: histórico, tecnologias e perspectivas. Viçosa: DFT, 2004. p. 195-196.

EMPRESA BRASILEIRA DE PESQUISA AGROPECUÁRIA. Sistema brasileiro e classificação de solos. Rio de Janeiro: Embrapa Solos, 1999. 412 p.

FILGUEIRA, F. A. R. Novo manual de olericultura: agrotecnologia moderna na produção e comercialização de hortaliças. Viçosa: UFV, 2003. 412 p.

GOTO, R. A cultura de alface. In: GOTO, R.; TIVELLI, S. W. Produção de hortaliças em ambiente protegido: condições subtropicais. São Paulo: Unesp, 1998. p. 137-159.

INSTITUTO DE ECONOMIA AGRÍCOLA. Estatísticas: preços pagos pela agricultura. Disponível em: <http:// WwWw.iea.sp.gov.br'?. Acesso em: 1 ago. 2006.

MATSUNAGA, M. Metodologia de custo de produção utilizada pelo IEA. Agricultura, São Paulo, v. 1, n. 1, p. 123-140, 1976.

OLIVEIRA, E. Q.; BEZERRA NETO, F.; NEGREIROS, M. Z.; GRANJEIRO, L. C.; BARROS JÚNIOR, A.; LIMA, J. S. S.; FREITAS, K. K. C. Viabilidade produtiva de cenoura em cultivo solteiro e consorciado com rúcula e alface em Mossoró-RN. In: CONGRESSO BRASILEIRO DE OLERICULTURA, 45., 2005, Fortaleza, CE. Anais... Fortaleza, 2005. CD-ROM. 
RESENHA meteorológica do período 1971-2000. Disponível em: ${ }^{-}\langle\mathrm{http}: / / \mathrm{w} w \mathrm{w}$. fcay unesp.br/departamentos icienciasexatas/caract/estacao/resenha71_00.htm em: 24 fev. 2007.

REZENDE, B. L. A.; CECÍLIO FILHO, A. B.; CATELAN, F.; MARTINS, M. I. E. G. Análise econômica de cultivos consorciados de alface americana $\mathrm{x}$ rabanete: um estudo de caso. Horticultura Brasileira, Brasília, v. 23, n. 3, p. $853-858$, jul./set. 2005a.

REZENDE, B. L. A.; CECÍLIO FILHO, A. B.; MARTINS, M. I. E. G.; COSTA, C. C.; FELTRIM, A. L. Viabilidade econômica das culturas de pimentão, repolho, alface, rabanete e rúcula em cultivo consorciado, na primaveraverão, Jaboticabal, Estado de São Paulo. Informações Econômicas, São Paulo, v. 35, n. 3, p. 22-37, mar. 2005b.

REZENDE, B. L. A.; COSTA, C. C.; CECÍLIO FILHO, A. B.; MARTINS, M. I. E. G. Custo de produção e rentabilidade da alface crespa, em ambiente protegido, em cultivo solteiro e consorciado com tomateiro, Jaboticabal, estado de São Paulo. Informações Econômicas, São Paulo, v. 35, n. 7, p. 42-50, jul. 2005c.

TRANI, P. E.; PASSOS, F. A.; AZEVEDO FILHO, J. A. de. Alface, almeirão, chicória, escarola, rúcula e agrião d'água. In: RAIJ, B. van; CANTARELLA, H.; QUAGGIO, J. A.; FURLANI, A. M. C. Recomendação de adubação e calagem para o estado de São Paulo. Campinas: IAC, 1997a. p. 168.

TRANI, P. E.; PASSOS, F. A.; MELO A. M. T.; SCIVITTARO, W. B.; NAGAI, H. Abobrinha ou abóbora de moita; abóbora rasteira, moranga e híbridos; bucha e pepino. In: RAIJ, B. V. van; CANTARELLA, H.; QUAGGIO, J. A.; FURLANI, A. M. C. Recomendações de adubação e calagem para o Estado de São Paulo. Campinas: IAC, 1997b. p. 165 .

VIEIRA, C. Cultivos consorciados. In: VIEIRA, C.; PAULA JÚNIOR, T. J.; BORÉM, A. Feijão: aspectos gerais e cultura no Estado de Minas Gerais. Viçosa: UFV, 1998. p. 523-558. 